\title{
EFFECTS OF GRAPHENE OXIDE ON THE HYDRATION OF TRICALCIUM SILICATE
}

\author{
KAI ZHENG*, **, ZHAOHENG GUO****, "NA CUI**, "\#INFEI LI*, ***, LICHAO FENG***** \\ *Shandong Provincial Key Laboratory of Preparation and Measurement of Building Materials, University of Jinan, \\ Jinan, Shandong, China, 250022 \\ **School of Civil Engineering and Architecture, University of Jinan, Jinan, Shandong, 250022, China \\ ***State Key Laboratory of Green Building Materials, Beijing, 100024, China \\ ****China Construction Materials Technology Research Chengdu Co., Ltd, Chengdu 610221, China \\ *****School of Mechanical Engineering and Jiangsu Marine Resources Development Research Institute, \\ Jiangsu Ocean University, Lianyungang, Jiangsu, 222005, China \\ \#E-mail: cea_cuin@ujn.edu.cn, mse_liqf@ujn.edu.cn
}

Submitted November 6, 2019; accepted July 25, 2020

\begin{abstract}
Keywords: Graphene oxide, Tricalcium silicate, Hydration, Micro-structure
Nanomaterials have been applied for the modification of cement-based materials with a low-dosage addition in recent years. Graphene oxide $(G O)$ has been studied in many papers for use in cement-based materials with properties of a twodimensional sheet-like structure, its extraordinary mechanical properties, high aspect ratio and hydrophilicity. To study the effects of graphene oxide on the hydration of tricalcium silicate, the hydration heat, hydration products and micro-structure of a $C_{3} S-G O$ hydration system were studied in this paper. The results showed that GO increases the hydration heat by promoting the hydration rate of $C_{3} S$, though the $G O$ could not react with the $C_{3} S$ hydration products (such as the calcium hydroxide and $\mathrm{C}-\mathrm{S}-\mathrm{H}$ gel produced by the $\mathrm{C}_{3} \mathrm{~S}$ hydration). It was found that the addition of $\mathrm{GO}$ changes the crystallite size of the hydration products through observing the SEM image. The GO modified the morphology of the $C_{3} S$ hydration products and led to a more compacter structure.
\end{abstract}

\section{INTRODUCTION}

Cement-based materials are widely used for the infrastructure construction and in various other fields and many studies have focused on the performance improvement of cement-based materials [1-4]. A hot topic about how to make cement-based materials have an excellent early work performance, suitable mechanical properties and great durability have been brought to the public's attention. In recent years, nanomaterials were applied for the modification of cement-based materials with a low-dosage addition [5-7]. Nano-silica, nano-titanium-oxide and nano- calcium carbonate, etc. have been the most widely studied ones. Studies have shown that nano-improved cement-based materials have a better performance, mechanical properties and durability when compared without the addition of nanomaterials to cement-based materials. The nanoscale effects or pozzolanic reactivity significantly improved the hydration process, and then further improved the microstructure and mechanical properties of cementbased materials.

Recently, graphene oxide (GO) with the properties of a two-dimensional sheet-like structure, extraordinary mechanical properties, high aspect ratio and hydrophilicity [8-10] have been used for studies with cement-based materials [11-16]. The effects of graphene oxide on the performance of cement-based materials have been studied by many researchers [11-16]. Studies have shown that GO significantly improved the overall performance of cement-based materials. Xu et al. [17] found that the addition of $0.02 \mathrm{wt}$ \% GO increased the compressive strength of 28-day old cement pastes with a w/c of 0.35 by $29 \%$. A study by Newell, et al. [18] resulted in significantly improving the compressive strength of a cement paste at 28 days and indicated that GO was the most advantageous when added in combination with other nanomaterials. Some researchers [19-21] have reported that the strength improvement could be up to $47 \%$ when a GO dosage between 0.03 wt. $\%$ to 0.05 wt. $\%$ is added. Mokhtar et al [22] suggested that the pore structure of a cementitious matrix was refined with a GO addition. Some researches indicated that the strength increase and pore refining effects were mainly attributed to the accelerating effect on the cement hydration as it can provide additional nucleation sites, and then the formation of the cement hydration products was enhanced [23-25]. A high toughness [26] and elastic modulus [27] was also reported with GO-added cementbased materials. 
Although the addition of GO has been reported to improve the mechanical properties of cement-based materials, the influence mechanism has also been studied with a cement hydration system. The effects of GO on the hydration of $\mathrm{C}_{3} \mathrm{~S}$ (tricalcium silicate, the main mineral composition of cement) should also be studied. In this paper, the effects of different graphene oxide dosages on the hydration of $\mathrm{C}_{3} \mathrm{~S}$ were studied. The heat of the hydration analysis, hydration phase composition and micro-scale morphology of the $\mathrm{GO}$-added $\mathrm{C}_{3} \mathrm{~S}$ hydration system are presented and discussed.

\section{EXPERIMENTAL}

Synthesis and characterisation of $\mathrm{C}_{3} \mathrm{~S}$

In this study, $\mathrm{C}_{3} \mathrm{~S}$ was synthesised by the sol-gel method. The tricalcium silicate sol was prepared by tetraethyl orthosilicate (TEOS) and calcium nitrate tetra-

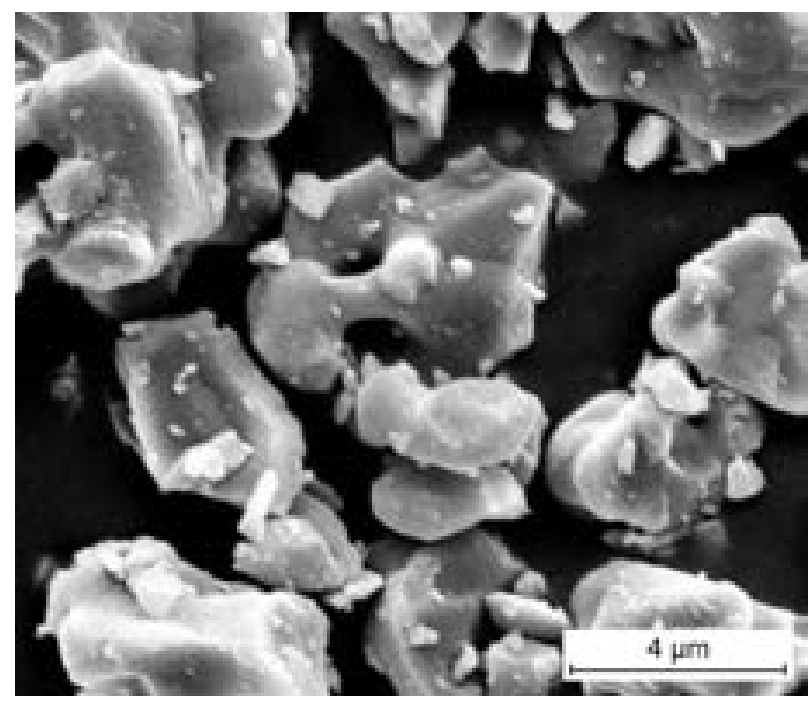

Figure 1. SEM image of the synthesised $\mathrm{C}_{3} \mathrm{~S}$.

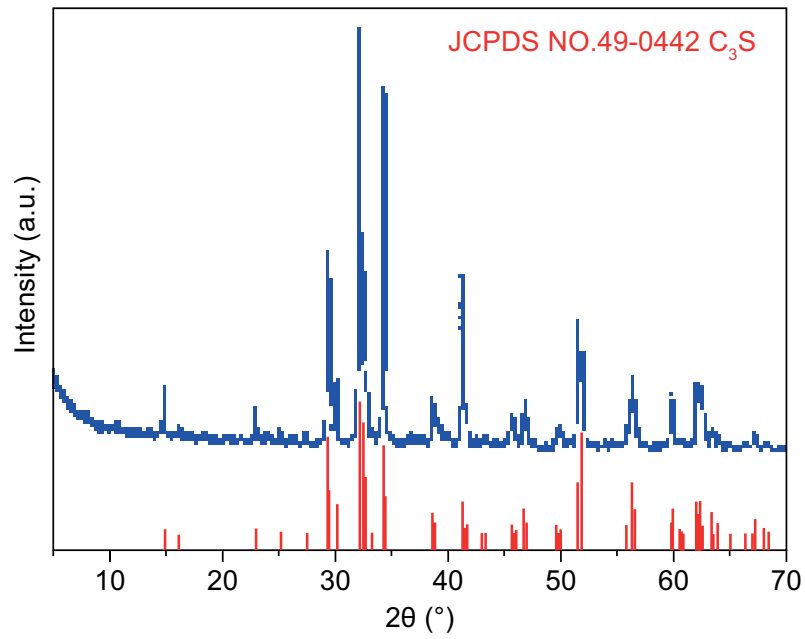

Figure 2. XRD spectra of the synthesised $\mathrm{C}_{3} \mathrm{~S}$. hydrate $\left(\mathrm{Ca}\left(\mathrm{NO}_{3}\right)_{2} \cdot 4 \mathrm{H}_{2} \mathrm{O}\right)$ with a $\mathrm{Ca} / \mathrm{Si}$ ratio of $3: 1$, and the tricalcium silicate sol was pre-sintered for $1 \mathrm{~h}$ at $540{ }^{\circ} \mathrm{C}$. Then, the tricalcium silicate sol was calcined at $1450{ }^{\circ} \mathrm{C}$ in a high-temperature furnace for $12 \mathrm{~h}$. Calcined $\mathrm{C}_{3} \mathrm{~S}$ was finely powdered in an agate mortar up to the specific surface area of $450 \mathrm{~m}^{2} \cdot \mathrm{kg}^{-1}$. The SEM (scanning electron microscopy) image of the $\mathrm{C}_{3} \mathrm{~S}$ is shown in Figure 1, while irregular particles can be seen. The XRD (X-ray diffraction) spectra results are shown in Figure 2, the purity of the $\mathrm{C}_{3} \mathrm{~S}$ following the standard of the card No. 49-0442. Table 1 shows the chemical composition of the synthesised $\mathrm{C}_{3} \mathrm{~S}$ and an $\mathrm{f}-\mathrm{CaO}$ content of $0.15 \%$ was allowed. The molar ratio of $\mathrm{CaO}$ and $\mathrm{SiO}_{2}$ was approximately 3.0.

Table 1. Chemical composition of the synthesized $\mathrm{C}_{3} \mathrm{~S}$ (wt. \%).

\begin{tabular}{lccc}
\hline Sample & $\mathrm{CaO}$ & $\mathrm{SiO}_{2}$ & $\mathrm{f}-\mathrm{CaO}$ \\
\hline $\mathrm{C}_{3} \mathrm{~S}$ & 71.82 & 25.21 & 0.15 \\
\hline
\end{tabular}

\section{Synthesis and characterisation of $\mathrm{C}_{3} \mathrm{~S}$}

Graphene oxide (GO) was provided by the Shanghai alighting biochemical technology co., LTD, China. The SEM image is shown in Figure 3 and the slice layer of the GO can be seen. The TEM (transmission electron microscopy) image of the graphene oxide is shown in Figure 4. High-intensity ultrasonication was used for the slice layer stripping of the graphene oxide for $5 \mathrm{~min}$. The TEM image in Figure 4 clearly shows the ultra-thin and well-dispersed GO nanosheets. AFM (atomic force microscopy) was used to determine the thickness of the GO and Figure 5 shows the AFM image of the GO, about $1.5 \mathrm{~nm}$ of the GO sheets are shown, which also indicates that the GO nanosheets are well-dispersed.

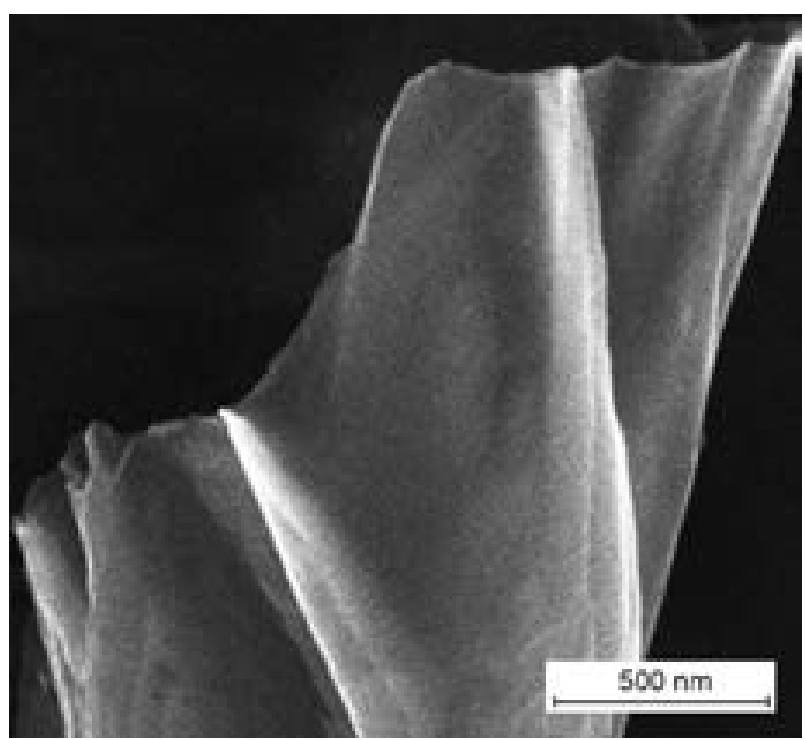

Figure 3. SEM image of the GO.

Ceramics - Silikáty 64 (4) 460-468 (2020) 


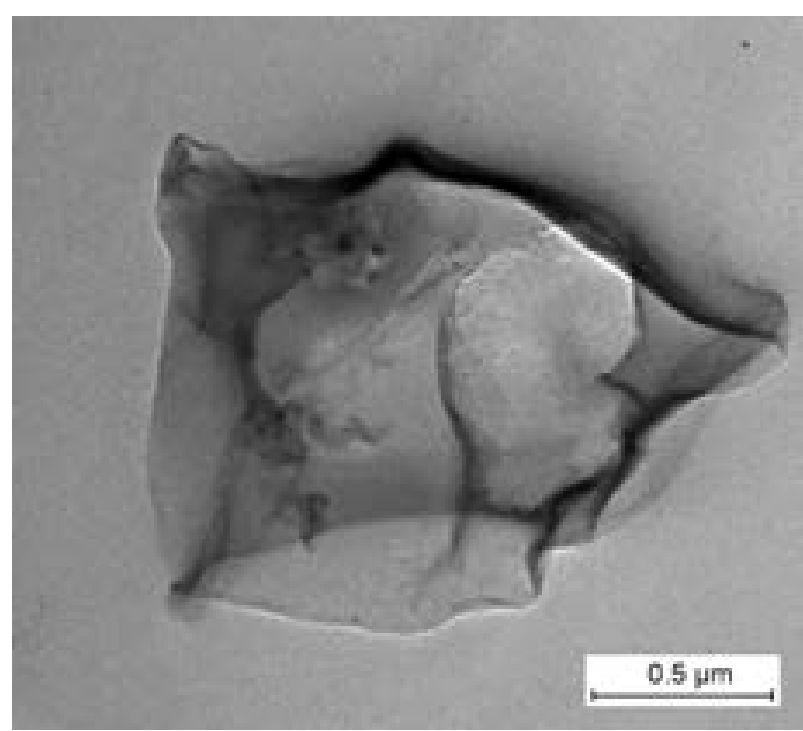

a)

Figure 4. TEM images of the GO.

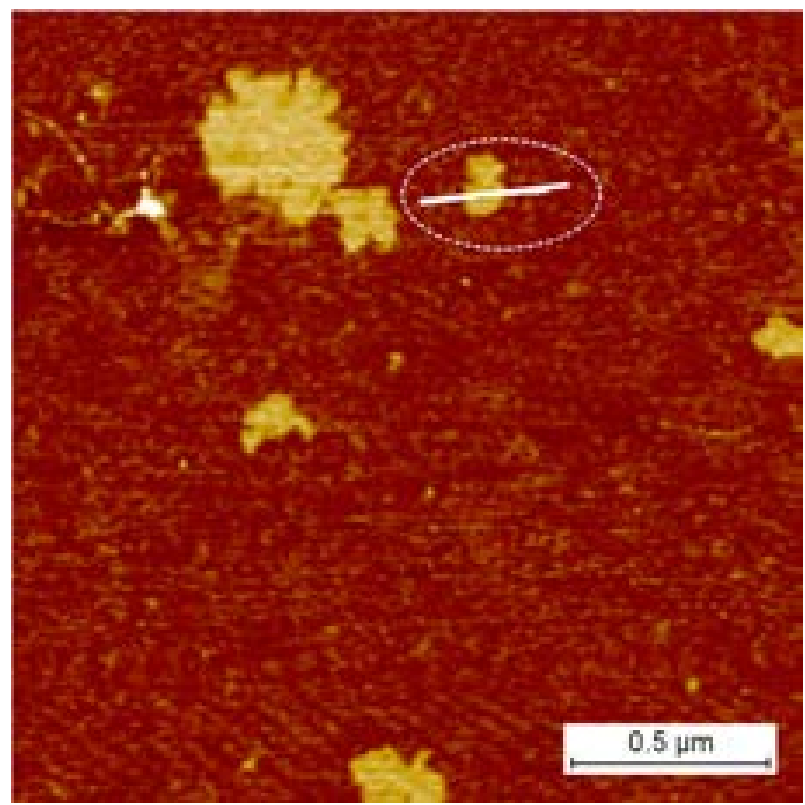

a)

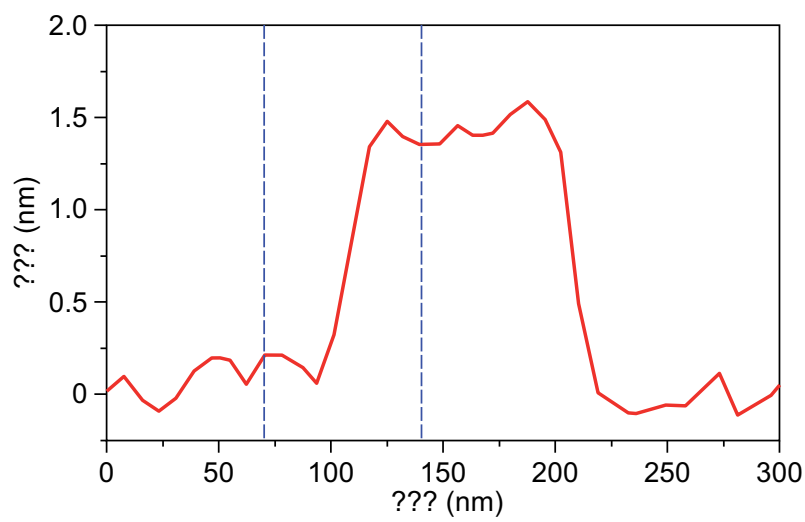

b)

Figure 5. AFM image of the GO.

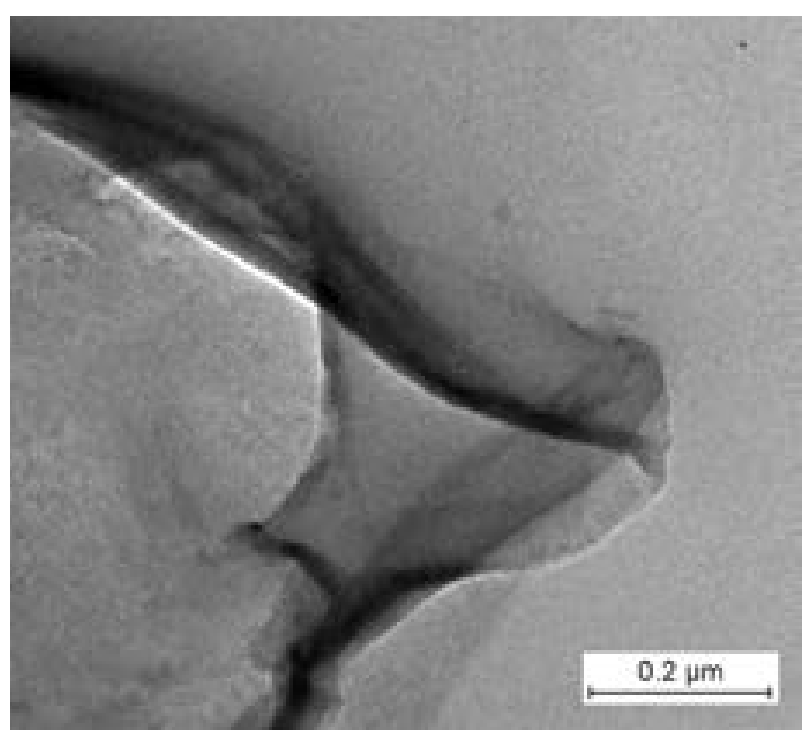

b)

The mix proportions of the $\mathrm{C}_{3} \mathrm{~S}-\mathrm{GO}$ hydration system are shown in Table 2 . A w/b of 20 was used to ensure the good dispersion of the $\mathrm{GO}$ and interaction with the $\mathrm{C}_{3} \mathrm{~S}$. GO was ultrasonically dispersedin water for 5 minutes before being added into the mixer. The GO solution was mixed with the $\mathrm{C}_{3} \mathrm{~S}$ in a pycnometer and then cured in a standard chamber $\left(20^{\circ} \mathrm{C} / 95 \% \mathrm{RH}\right.$ 9 relative humidity)) for $6 \mathrm{~h}, 12 \mathrm{~h}, 18 \mathrm{~h}, 3 \mathrm{~d}$ and $7 \mathrm{~d}$ before the test, a vacuum environment was needed for the curing. After curing for a certain amount of time, the samples were prepared for the SEM and XRD tests.

Table 2. Mix proportions of the $\mathrm{C}_{3} \mathrm{~S}-\mathrm{GO}$ samples.

\begin{tabular}{lccc}
\hline Samples & w/b & $\mathrm{C}_{3}$ S (wt. \%) & GO (wt. \%) \\
\hline Control & 20 & 100 & - \\
GO0.1 & 20 & 99.9 & 0.1 \\
GO0.2 & 20 & 99.8 & 0.2 \\
GO0.3 & 20 & 99.7 & 0.3 \\
\hline
\end{tabular}

Test methods

\section{Heat flow Ccalorimetry}

A TAM air isothermal calorimeter (Thermometric $\mathrm{AB}$, Sweden) was used for the heat flow calorimetry test. $\mathrm{A}$ w/b of 20 was used in this test as shown in Table 2. The GO was ultrasonically dispersed in the mixing water for 5 minutes before being added into the mixture. The mixes were cast in $5.08 \mathrm{~cm} \times 10.16 \mathrm{~m}$ plastic cylinders within 3 min after the initial cement and water contact. Then, the sample was covered, placed in the calorimeter, and recorded every $3 \mathrm{~min}$ for $48 \mathrm{~h}$ at $25^{\circ} \mathrm{C}$. 


\section{$X$-Ray diffraction}

The hydration phase of the $\mathrm{C}_{3} \mathrm{~S}-\mathrm{GO}$ system was studied by X-ray diffraction (XRD, Bruker D8 Advance, Germany). Alcohol was used to terminate the hydration. The samples were vacuum oven-dried at $45^{\circ} \mathrm{C}$ for $48 \mathrm{~h}$ and then ground into a powder smaller than $75 \mu \mathrm{m}$. $\mathrm{Cu}-\mathrm{Ka}$ radiation was applied at a voltage of $40 \mathrm{kV}$ and an accelerating current of $40 \mathrm{~mA}$. A scan speed of $0.5 \mathrm{sec} /$ step and an increment of $0.02^{\circ}$ was used.

\section{Morphology and microstructure characterisation}

Scanning electron microscopy (SEM) was used to observe the effects of the GO on the hydration products. The hydration process in the samples were terminated by alcohol and then vacuum oven-dried at $45{ }^{\circ} \mathrm{C}$ for $48 \mathrm{~h}$ before testing. The samples were made conductive by coating a gold film $20 \mathrm{~nm}$ thick to ensure better conductivity.

\section{RESULTS AND DISCUSSIONS}

\section{Heat flow calorimetry of $\mathrm{C}_{3} \mathrm{~S}-\mathrm{GO}$ hydration system}

The heat flow of the $\mathrm{C}_{3} \mathrm{~S}$ hydration system with the GO is shown in Figure 6. It was demonstrated that the addition of GO increases both the hydration peak flow and the hydration rate. The hydration heat release of the samples with the GO addition was higher than that of the control sample. The promoting effects were due to the extra hydrate nucleation sites proved by the GO. GO retards the occurrence of the hydration heat flow peak when compared to the control samples, which might be due to fact that the hydration was promoted and more hydration products were formed, it might coat the surface of unhydrated particles and hinder the hydration of unhydrated particles. With the increase in the added dosage of GO, the heat flow peak showed

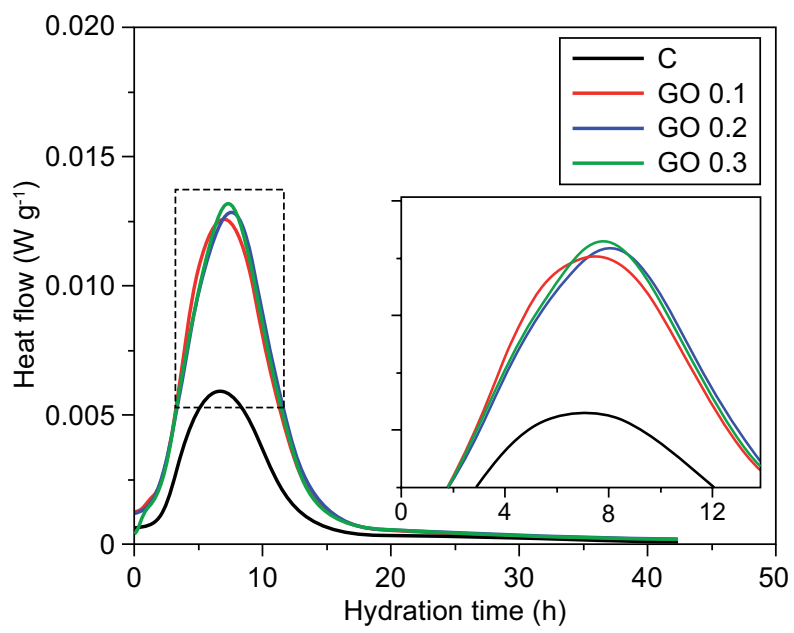

Figure 6. Heat flow of the $\mathrm{C}_{3} \mathrm{~S}$ hydration as a function of time. a backward migration. A study by Lu et al. [25] showed the same improvement in the dissolution and hydration of the cement into water. As reported by Zhang et al. [28], the rapid nucleation and growth of the hydrates were revealed in the acceleration period (the second heat peak). At any time in the acceleration period, Cheung et al. [29] suggested that the maximum heat flow peak in the acceleration period was associated with the number of hydrate nucleation sites. It is known that the incorporation of GO improved the hydration rate with the heat flow of the hydration. The acceleration effects of the GO were attributed to the nucleation effect of the nanoscale GO.

Figure 7 shows the cumulative heat of the $\mathrm{C}_{3} \mathrm{~S}$ hydration system, the obvious higher heat was shown in the GO-added samples when compared to the control samples. It also confirmed that the addition of GO could promote the hydration of $\mathrm{C}_{3} \mathrm{~S}$. These results also revealed that more hydration products were formed as more heat was produced with the GO-added hydration system. The study by $\mathrm{Lu}$ et al. [25] researched the chemical interaction between the GO and cement and detected the newly generated hydration product of $\mathrm{Ca}(\mathrm{HCOO})_{2}$, which indicated that the $\mathrm{Ca}(\mathrm{OH})_{2}$ produced by hydration of $\mathrm{C}_{3} \mathrm{~S}$ could be consumed by the $\mathrm{GO}$, and more hydration products were formed at an early age. This was the same with the results of the $\mathrm{C}_{3} \mathrm{~S}-\mathrm{GO}$ hydration system. It could also be seen that the GO0.2 samples showed the highest heat. However, the GO0.3 samples showed lower heat than the GO0.2 samples, the agglomeration of the GO particles with the large dosage amount added might have contributed to these results, as the promoting effects were reduced.

\section{Hydration products of $\mathrm{C}_{3} \mathrm{~S}-\mathrm{GO}$}

The X-ray diffraction hydration products of $\mathrm{C}_{3} \mathrm{~S}$ with the different added GO dosages are shown in Figures 8 and 9. Figure 8 shows the XRD spectra with

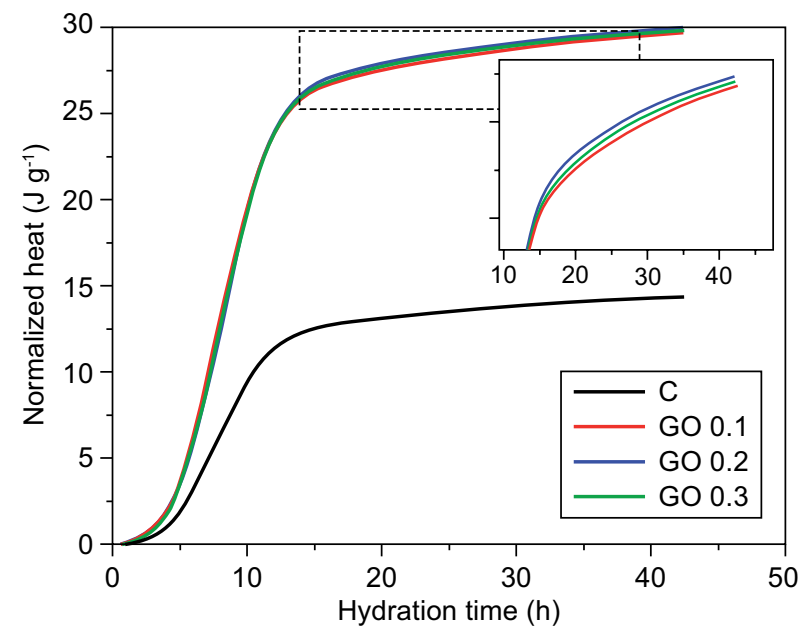

Figure 7. Cumulative heat of hydration of the $\mathrm{C}_{3} \mathrm{~S}-\mathrm{GO}$ system. 
a hydration time of $12 \mathrm{~h}$, it can be seen that the higher intensity peak of the portlandite between $15^{\circ}$ to $20^{\circ}$ is shown by the $0.1 \%$ GO samples when compared to the control samples, which indicated that the GO promoted the hydration of $\mathrm{C} 3 \mathrm{~S}$ and this result was consistent with the rate of the $\mathrm{C}_{3} \mathrm{~S}$ hydration result in Figures 6 and 7. When the GO added dosage increased to $0.2 \%$ and $0.3 \%$, the intensity of the portlandite decreased, this might be due to the poor dispersion of the GO was a result of the higher added dosage. Some researchers [30] suggested that amorphous $\mathrm{CH}$ or grain-refined $\mathrm{CH}$ is highly cemented with other hydration products in a GO added hydration system when compared to crystalline $\mathrm{CH}$ with a better crystal shape and the GO might modify the crystalline size of the $\mathrm{CH}$.

Figure 9 shows the XRD spectra of $\mathrm{C}_{3} \mathrm{~S}$ at a hydration of $7 \mathrm{~d}$, a higher $\mathrm{CH}$ content could be seen in the samples with the GO addition, which increased with the GO-added dosage. The promoting effects of GO and modified $\mathrm{CH}$ crystalline size might have contributed to this result. The same results were also shown in the Qureshi et al [31] study at the curing age of 7 days of a cement hydration system. Meanwhile, the shift of the $\mathrm{CH}$ angle is shown in Figure 9, which indicated that the effects of the $\mathrm{GO}$ on the $\mathrm{C}_{3} \mathrm{~S}$ hydration were not only in promoting the hydration. The same shift in the $\mathrm{CH}$ peak with the added GO was shown in the study of Wang et al [30].

\section{Morphology and microstructure characterisation}

The microstructure of the $\mathrm{C}_{3} \mathrm{~S}$ hydration system with the different times $(6 \mathrm{~h}, 18 \mathrm{~h}, 3 \mathrm{~d}$ and $7 \mathrm{~d})$ and GO-added dosages $(0.1 \%, 0.2 \%, 0.3 \%)$ is shown in Figures 10, 11 and 12 . From the hydration process of $\mathrm{C}_{3} \mathrm{~S}$ in Figure 10, it can be seen that the surface of the $\mathrm{C}_{3} \mathrm{~S}$ particles was covered by a layer of gelatinous hydration products and some of the particles grow needle-like hydration products of $\mathrm{C}-\mathrm{S}-\mathrm{H}$ gel after $6 \mathrm{~h}$ of hydration. Higher density hydration products were shown by the GO0.1 and GO0.2 samples, which was due to the fact that GO improved the dissolution and reaction of the $\mathrm{C}_{3} \mathrm{~S}$ in the water solution. More hydration products were formed and they showed a more compact structure around the $\mathrm{C}_{3} \mathrm{~S}$ particle. The GO0.3 samples showed a similar structure compactness to control samples, the poor dispersion of the GO and large amount of GO that took up the $\mathrm{C}_{3} \mathrm{~S}$ hydration space might have contributed to this result which was consistent with the XRD results in Figure 8.

When the hydration time increased to $18 \mathrm{~h}$, the most compact structure was also shown by the GO0.1 and GO0.2 samples. Meanwhile, the small size hydration products were shown in the $\mathrm{GO}-\mathrm{C}_{3} \mathrm{~S}$ hydration system when compared to the control samples. The arrangement and accumulation of smaller size hydration products led to a denser micro-structure. An obvious layer structure was found when the hydration time increased to 7 days, and a better structure was shown by the GO0.1 and GO0.2 samples. The needle-like hydration products were connected and the structure was more compact than the hydration time of $6 \mathrm{~h}$ and $18 \mathrm{~h}$.

\section{CONCLUSIONS}

In this study, the effects of graphene oxide on the hydration of $\mathrm{C}_{3} \mathrm{~S}$ were studied through the hydration heat, hydration products and microstructure with $0.1 \mathrm{wt} . \%$, 0.2 wt. $\%$ and 0.3 wt. $\%$ added GO dosages. The key findings are summarised as follows:

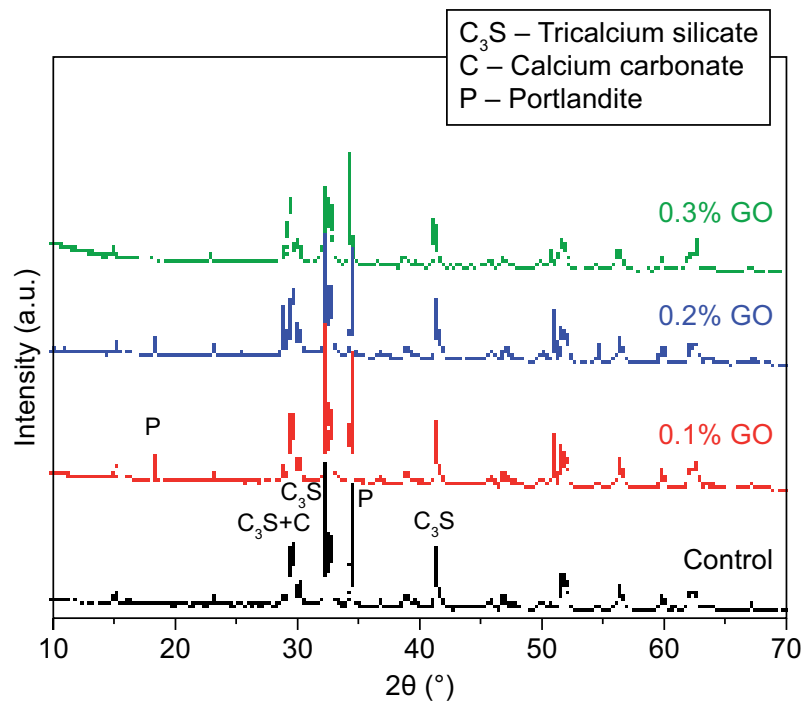

Figure 8. XRD spectra of the $\mathrm{C}_{3} \mathrm{~S}$ at a hydration of $12 \mathrm{~h}$ with different $\mathrm{GO}$ dosage additions.

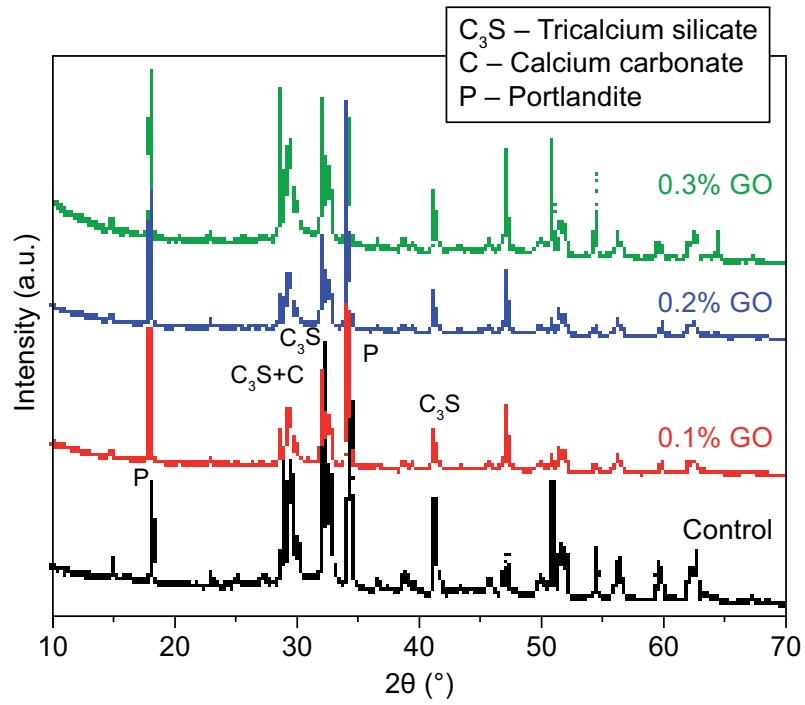

Figure 9. XRD spectra of the $\mathrm{C}_{3} \mathrm{~S}$ at a hydration of $7 \mathrm{~d}$ with different GO dosage additions. 


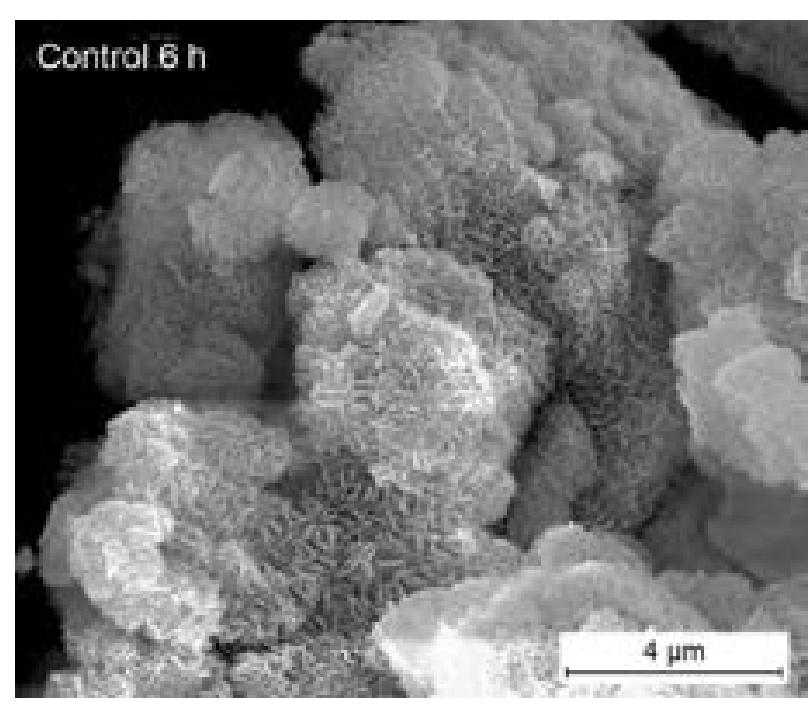

a)

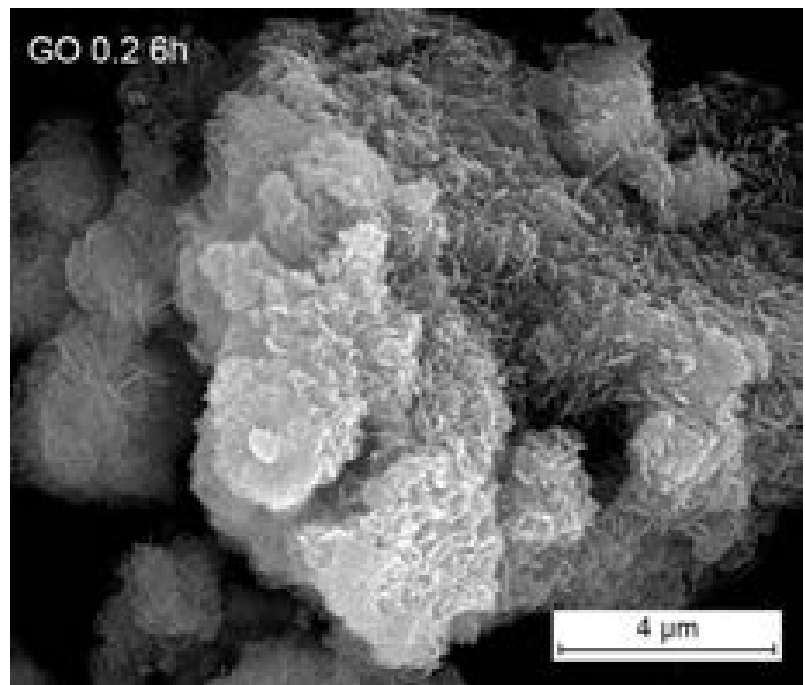

c)

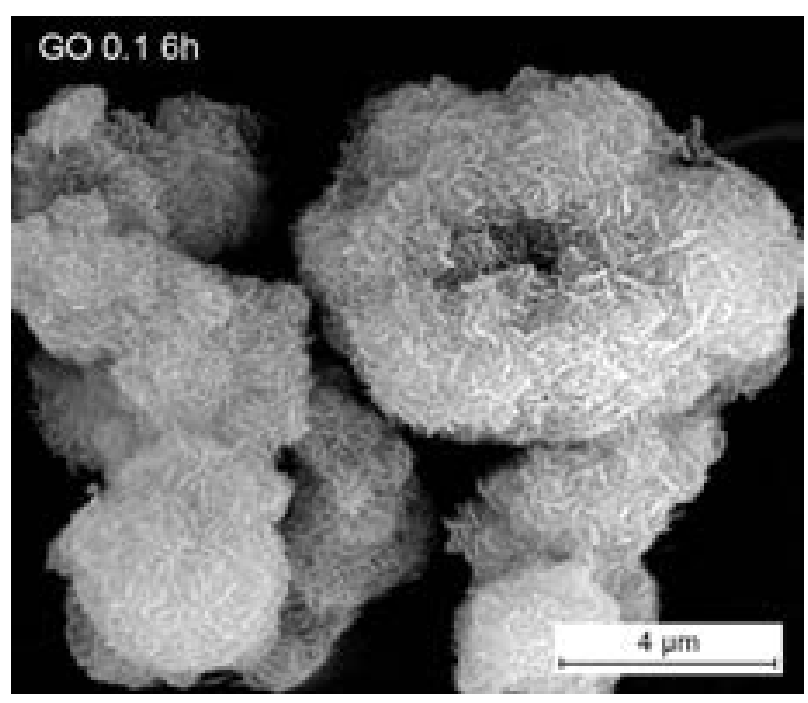

b)

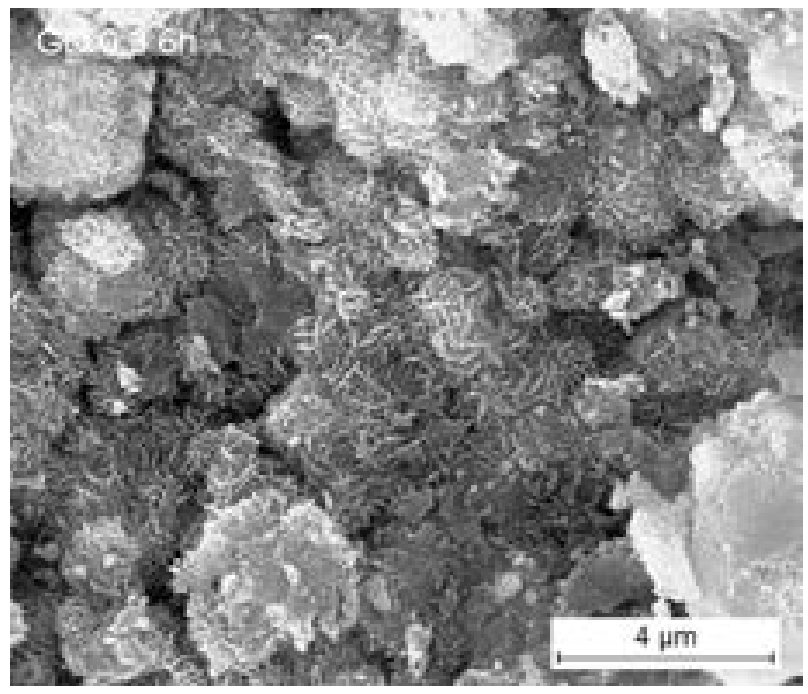

d)

Figure 10. SEM images of the $\mathrm{C}_{3} \mathrm{~S}$ hydrated for $6 \mathrm{~h}$ with different $\mathrm{GO}$ dosage additions: a) Control; b) 0.1 wt. \% GO; c) 0.2 wt. \% GO; d) 0.3 wt. \% GO.

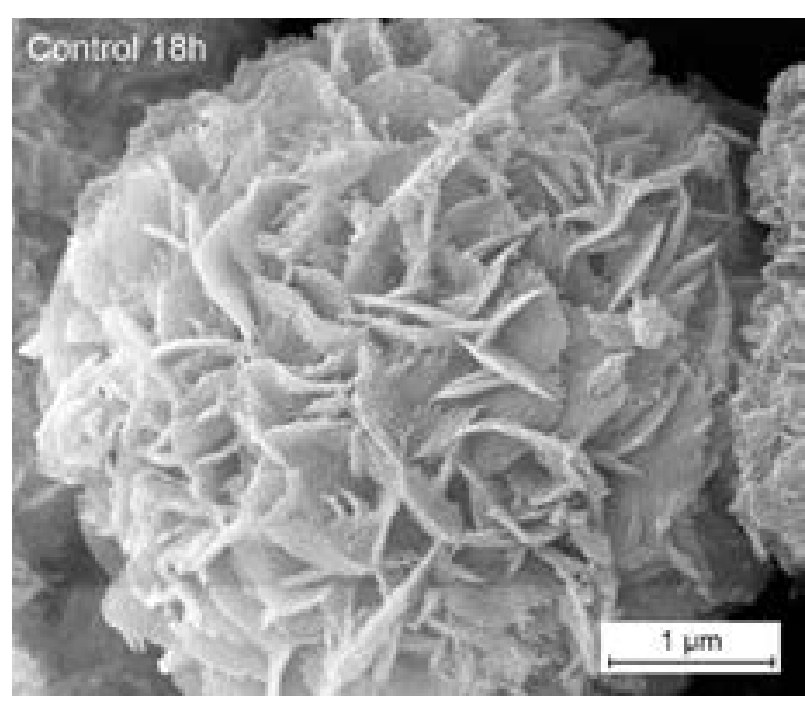

a)

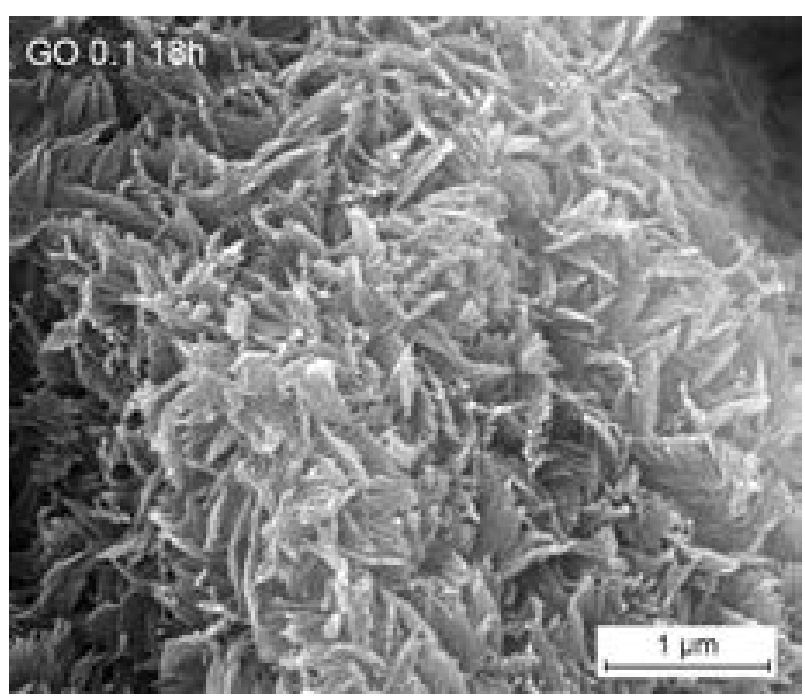

b)

Figure 11. SEM images of the $\mathrm{C}_{3} \mathrm{~S}$ hydrated for $18 \mathrm{~h}$ with different GO dosage additions: a) Control; b) $0.1 \mathrm{wt} \%$ GO. 


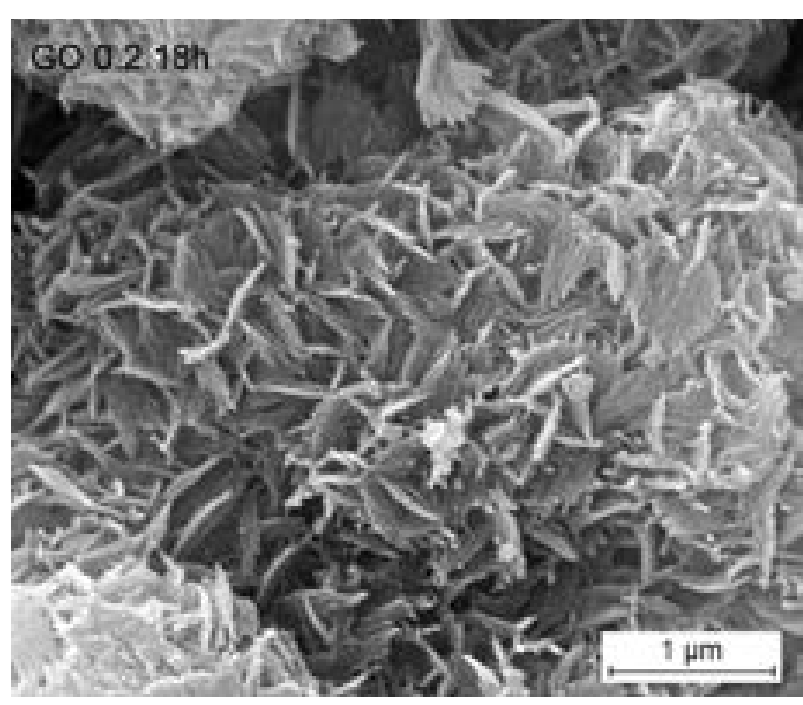

c)

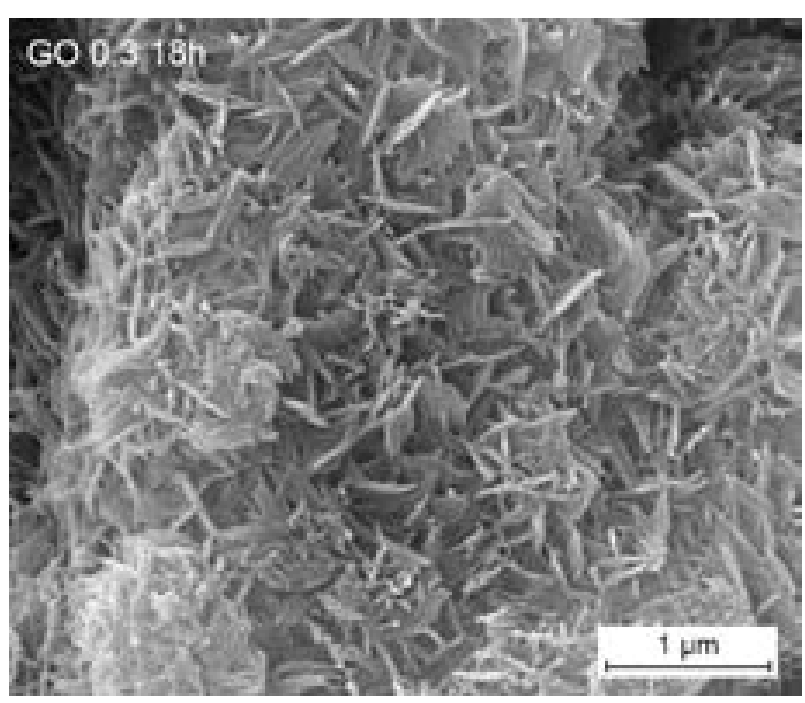

d)

Figure 11. SEM images of the $\mathrm{C}_{3} \mathrm{~S}$ hydrated for $18 \mathrm{~h}$ with different GO dosage additions: c) $0.2 \mathrm{wt}$ \% GO; d) 0.3 wt. $\%$ GO.

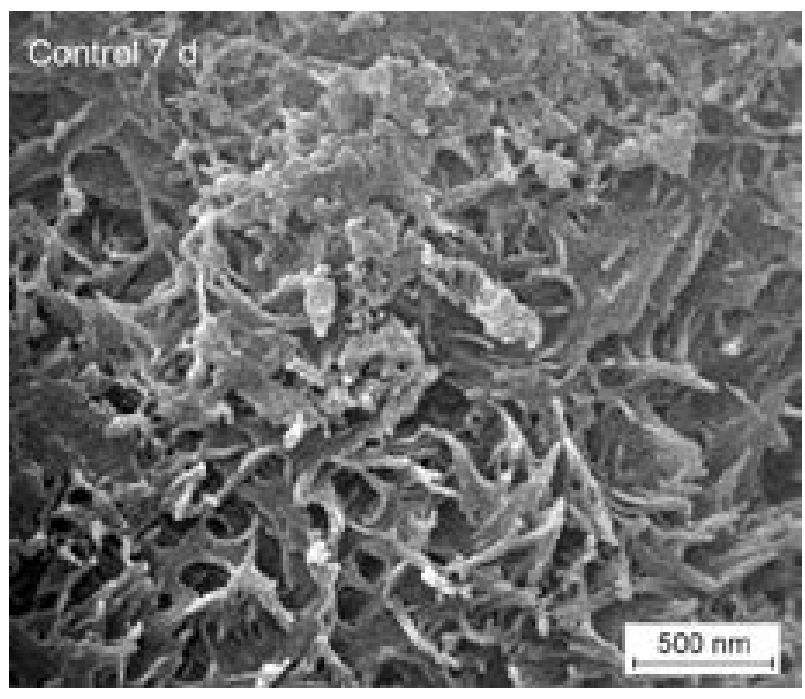

a)

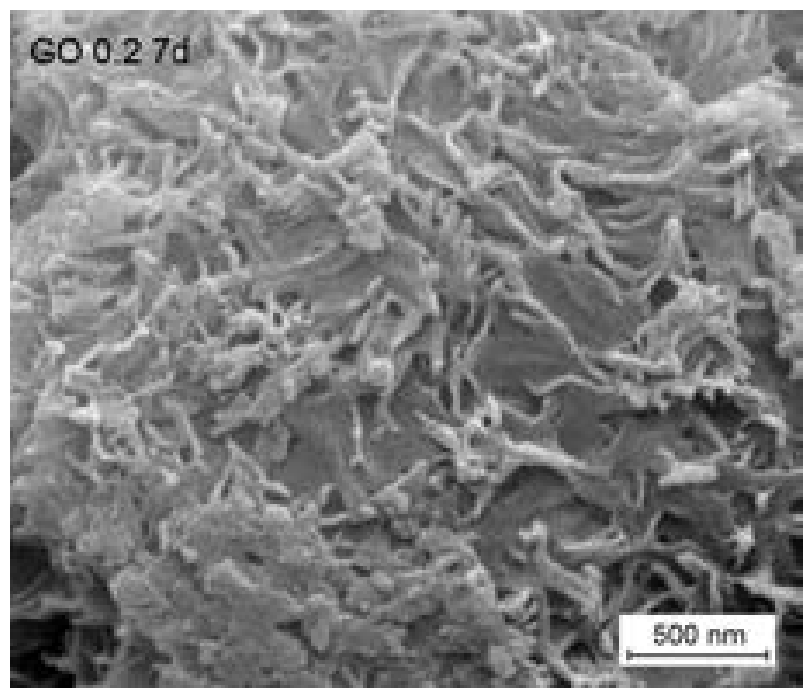

c)

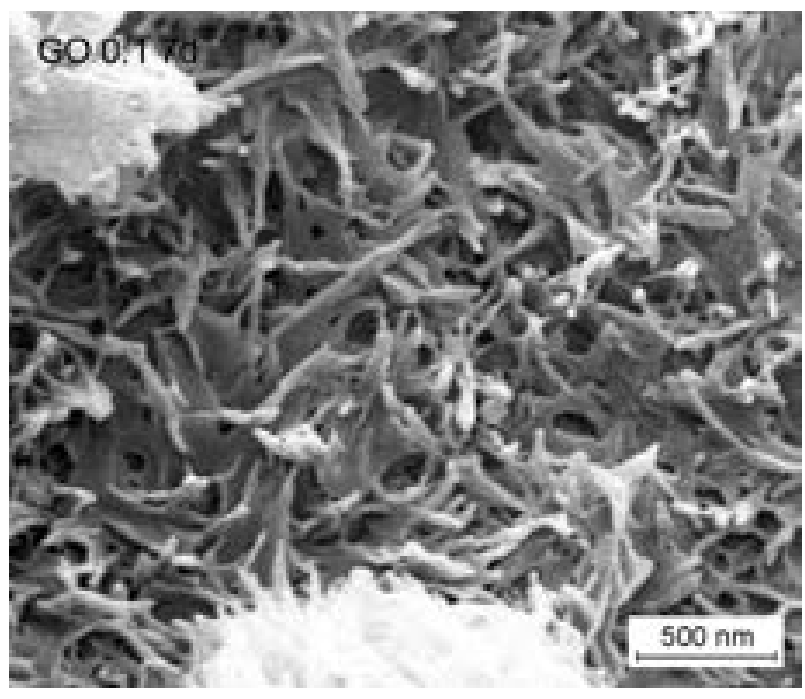

b)

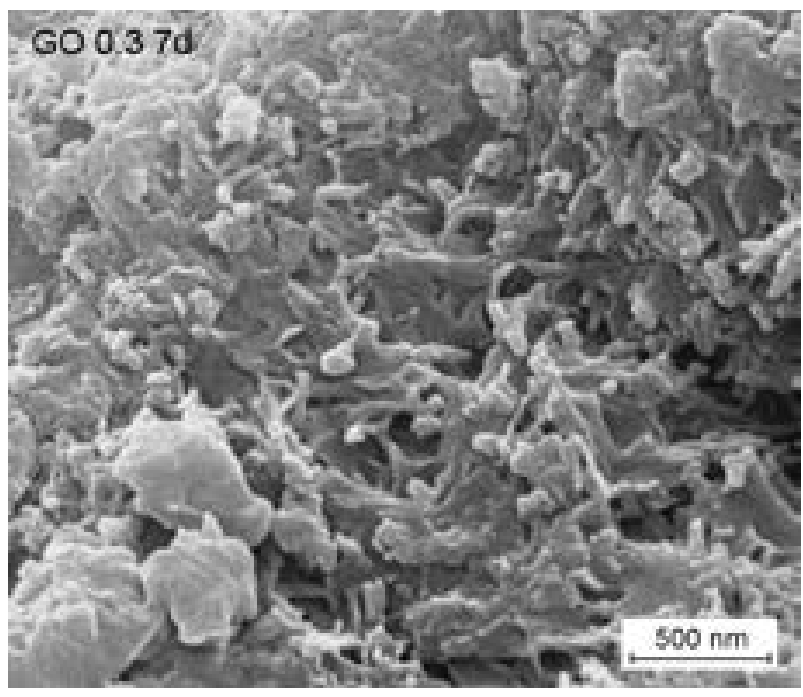

d)

Figure 12. SEM images of the $\mathrm{C}_{3} \mathrm{~S}$ hydrated for $7 \mathrm{~d}$ with different GO dosage additions: a) Control; b) 0.1 wt. \% GO; c) 0.2 wt. \% GO; d) 0.3 wt. $\%$ GO. 
- GO could accelerate the hydration of $\mathrm{C}_{3} \mathrm{~S}$ and promote the hydration rate, though the GO could not react with the $\mathrm{C}_{3} \mathrm{~S}$ hydration products and only modified the hydration process.

- The addition of GO changed the crystalline size of the $\mathrm{CH}$ produced by the $\mathrm{C}_{3} \mathrm{~S}$ hydration and promoted effects of the $\mathrm{GO}$ caused more $\mathrm{CH}$ to be formed.

- The GO modified the morphology of the $\mathrm{C}_{3} \mathrm{~S}$ hydration products and led to a more compact structure when compared to the control samples. A suitable added dosage of $\mathrm{GO}$ is needed as the $\mathrm{GO}$ particles might become agglomerated at a large dosage amount and the improvement will be cut down.

\section{Acknowledgments}

Funding for this project was provided by the National Natural Science Foundation of China (71874069, 51632003, and 51761145023), 111 Project of International Corporation on Advanced Cement-based Materials (No. D17001), the Taishan Scholars Program, Youth Innovation Support Program of Shandong Colleges and Universities, Shandong Province Higher Educational Science and Technology Program (J17KA003-A), Lianyungang Gaoxin District International Scientific Cooperation Program (HZ201902), and the Opening Project of State Key Laboratory of Green Building Materials.

\section{REFERENCES}

1. Singh L. P., Bhattacharyya S. K., Shah S. P., Mishra G., Ahalawat S., Sharma, U. (2015): Studies on early stage hydration of tricalcium silicate incorporating silica nanoparticles: Part I. Construction and Building Materials, 74, 278-286. doi: 10.1016/j.conbuildmat.2014.08.046

2. Alizadeh R., Beaudoin J. J., Raki L. (2011): Mechanical properties of calcium silicate hydrates. Materials and Structures, 44(1), 13-28.doi: 10.1617/s11527-010-9605-9

3. Dyer T. (2014). Concrete durability. Crc Press.

4. Hooton R. D. (2019): Future directions for design, specification, testing, and construction of durable concrete structures. Cement and Concrete Research, 124, 105827.doi 10.1016/ j.cemconres.2019.105827

5. Kawashima S., Hou P., Corr D. J., Shah S. P. (2013): Modification of cement-based materials with nanoparticles. Cement and Concrete Composites, 36, 8-15. doi: 10.1016/j. cemconcomp.2012.06.012

6. Liu J., Chen H., Guan B., Liu K., Wen J., Sun Z. (2018): Influence of mineral nano-fibers on the physical properties of road cement concrete material. Construction and Building Materials, 190, 287-293. doi: 10.1016/j. conbuildmat.2018.09.025

7. Patel M. M., Clevenger C. M., Abdallah M. (2018): Carbon nano-tube as water reducer in CDOT Class E $12 \mathrm{hr}$ concrete mix. Case Studies in Construction Materials, 9, e00207. doi: 10.1016/j.cscm.2018.e00207

8. Tung V. C., Allen M. J., Yang,Y., Kaner R. B. (2009): High- throughput solution processing of large-scale graphene. Nature nanotechnology, 4(1), 25. doi: 10.1038/nnano.2008. 329

9. Zandiatashbar A., Lee G. H., An S. J., Lee S., Mathew N., Terrones M.,et al. (2014): Effect of defects on the intrinsic strength and stiffness of graphene. Nature communications, 5(1), 1-9. doi: 10.1038/ncomms4186

10. Lee C., Wei X., Kysar J. W., Hone J. (2008): Measurement of the elastic properties and intrinsic strength of monolayer graphene. Science, 321(5887), 385-388. doi: 10.1126/ science. 1157996

11. Zhu Y., Murali S., Cai W., Li X., Suk J. W., Potts J. R., Ruoff R. S. (2010): Graphene and graphene oxide: synthesis, properties, and applications. Advanced Materials, 22(35), 3906-3924. doi: 10.1002/adma.201001068

12. Dikin D. A., Stankovich S., Zimney E. J., Piner R. D., Dommett G. H., Evmenenko G., et al. (2007): Preparation and characterization of graphene oxide paper. Nature, 448(7152), 457-460. doi: 10.1038/nature06016

13. Shamsaei E., de Souza F. B., Yao X., Benhelal E., Akbari A., Duan W. (2018): Graphene-based nanosheets for stronger and more durable concrete: A review. Construction and Building Materials, 183, 642-660.doi: 10.1016/j.conbuildmat.2018.06.201

14. Yang H., Cui H., Tang W., Li Z., Han N., Xing F. (2017): A critical review on research progress of graphene/cement based composites. Composites Part A: Applied Science and Manufacturing, 102, 273-296. doi: 10.1016/j.compositesa. 2017.07.019

15. Xu Y., Zeng J., Chen W., Jin R., Li B., Pan Z. (2018): A holistic review of cement composites reinforced with graphene oxide. Construction and Building Materials, 171, 291-302. doi: 10.1016/j.conbuildmat.2018.03.147

16. de Silva R. A., de Castro Guetti P., da Luz M. S., Rouxinol F., Gelamo R. V. (2017): Enhanced properties of cement mortars with multilayer graphene nanoparticles. Construction and Building Materials, 149, 378-385. doi: 10.1016/j.conbuildmat.2017.05.146

17. Xu G., Du S., He J., Shi X. (2019): The role of admixed graphene oxide in a cement hydration system. Carbon, 148, 141-150.doi: 10.1016/j.carbon.2019.03.072

18. Newell M., Garcia-Taengua E. (2019): Fresh and hardened state properties of hybrid graphene oxide/nanosilica cement composites. Construction and Building Materials, 221, 433-442. doi: 10.1016/j.conbuildmat.2019.06.066

19. Gong K., Pan Z., Korayem A. H., Qiu L., Li D., Collins F., et al. (2015): Reinforcing effects of graphene oxide on portland cement paste. Journal of Materials in Civil Engineering, 27(2), 1-6. doi: 10.1016/j.jobe.2020.101551

20. Wang Q., Wang J., Lu C. X., Liu B. W., Zhang K., Li C. Z. (2015): Influence of graphene oxide additions on the microstructure and mechanical strength of cement. New Carbon Materials, 30(4), 349-356. doi: 10.1016/S18725805(15)60194-9

21. Li X., Liu Y. M., Li W. G., Li C. Y., Sanjayan J. G., Duan W. H., Li Z. (2017): Effects of graphene oxide agglomerates on workability, hydration, microstructure and compressive strength of cement paste. Construction and Building Materials, 145, 402-410. doi: 10.1016/j.conbuildmat.2017. 04.058

22. Mokhtar M. M., Abo-El-Enein S. A., Hassaan M. Y., Morsy M. S., Khalil M. H. (2017): Mechanical performance, pore structure and micro-structural characteristics of graphene oxide nano platelets reinforced cement. Construction and 
Building Materials, 138, 333-339. doi: 10.1016/j.conbuildmat.2017.02.021

23. Lin C., Wei W., Hu Y. H. (2016): Catalytic behavior of graphene oxide for cement hydration process. Journal of Physics and Chemistry of Solids, 89, 128-133. doi: 10.1016/ j.jpcs.2015.11.002

24. Hou D., Lu Z., Li X., Ma H., Li Z. (2017): Reactive molecular dynamics and experimental study of graphenecement composites: Structure, dynamics and reinforcement mechanisms. Carbon, 115, 188-208. doi: 10.1016/j.carbon. 2017.01.013

25. Lu Z., Li X., Hanif A., Chen B., Parthasarathy P., Yu J., Li Z. (2017): Early-age interaction mechanism between the graphene oxide and cement hydrates. Construction and Building Materials, 152, 232-239. doi: 10.1016/j.conbuildmat.2017.06.176

26. Ranjbar N., Mehrali M., Mehrali M., Alengaram U. J., Jumaat M. Z. (2015): Graphene nanoplatelet-fly ash based geopolymer composites. Cement and Concrete Research, 76, 222-231. doi: 10.1016/j.cemconres.2015.06.003

27. Kiamahalleh M. V., Gholampour A., Tran D. N., Ozbakkaloglu T., Losic D. (2020): Physiochemical and mechanical properties of reduced graphene oxide-cement mortar composites: Effect of reduced graphene oxide particle size. Construction and Building Materials, 250, 118832. doi: 10.1016/j.conbuildmat.2020.118832

28. Zhang Y. R., Kong X. M., Lu Z. B., Lu Z. C., Hou S. S. (2015): Effects of the charge characteristics of polycarboxylate superplasticizers on the adsorption and the retardation in cement pastes. Cement and Concrete Research, 67, 184196. doi: 10.1016/j.cemconres.2014.10.004

29. Cheung J., Jeknavorian A., Roberts L., Silva D. (2011): Impact of admixtures on the hydration kinetics of Portland cement. Cement and concrete research, 41(12), 1289-1309. doi: 10.1016/j.cemconres.2011.03.005

30. Wang Q., Li S., Pan S., Cui X., Corr D. J., Shah S. P. (2019): Effect of graphene oxide on the hydration and microstructure of fly ash-cement system. Construction and Building Materials, 198, 106-119. doi: 10.1016/j.conbuildmat.2018. 11.199

31. Quresh, T. S., Panesar D. K. (2019): Impact of graphene oxide and highly reduced graphene oxide on cement based composites. Construction and Building Materials, 206, 71-83. doi: 10.1016/j.conbuildmat.2019.01.176 